\title{
Prevalence, risk factors and clinical characteristics of renal dysfunction in Chinese outpatients with growth simple renal cysts
}

\author{
Qiaoru $\mathrm{Wu}^{1} \cdot$ Chunhua $\mathrm{Ju}^{2} \cdot$ Miaowen Deng ${ }^{3} \cdot$ Xiaolong $\mathrm{Liu}^{3} \cdot$ Zhongda $\mathrm{Jin}^{2} \odot$
}

Received: 28 March 2021 / Accepted: 11 November 2021 / Published online: 22 November 2021

(c) The Author(s) 2021

\begin{abstract}
Background Researchers have proved that simple renal cysts (SRCs) might be correlated with renal dysfunction, but it is still controversial. Thus, we conducted clinical research study with large sample size and long-term follow-up to clarify the relationship between SRCs and renal dysfunction.

Methods A total of 571 SRCs patients in outpatients of nephrology department were included, we investigated the clinical characteristics of growth SRCs compared with non-growth SRCs, evaluated the incidence of renal dysfunction in SRCs and explored the risk factors of renal dysfunction in growth SRCs.

Results The mean baseline age was $51.31 \pm 14.37$ years in the whole cohort, ranging from 19 to 79 years, and $57.6 \%$ of them were male. The median follow-up duration was 3 years, ranging from 1 to 10 years. In addition, the final maximum diameter increased $1 \mathrm{~mm}$ (2.74\%) per year. Patients in growth SRCs group tented to have higher percentage of hypertension, hematuria, large cyst and multiple cysts compared with non-growth SRCs group. The prevalence of renal dysfunction was $15.6 \%$ after the follow-up, and the prevalence of renal dysfunction was about 10 times higher in growth SRCs group than non-growth SRCs group (23.3\% vs. $2.4 \%$ ). Renal dysfunction was significantly associated with age, female, total cholesterol, diastolic blood pressure, final maximum diameter and yearly change in maximum diameter in growth SRCs.

Conclusions SRCs were closely related to the decline of renal function, we recommend close follow-up for growth SRCs.
\end{abstract}

Keywords Growth simple renal cysts $\cdot$ Renal dysfunction $\cdot$ Prevalence $\cdot$ Risk factors $\cdot$ Clinical characteristics

\section{Introduction}

Kidneys play a vital role in maintaining fluid, electrolyte, and acid-base balance. The loss of renal function could lead to internal environmental disorders and develop into cardiovascular events. Moreover, hypertension, obesity, diabetes

Qiaoru Wu and Chunhua Ju have contributed equally.

Zhongda Jin

tggzzyydx@126.com

1 Department of Nephrology, Dongzhimen Hospital, Beijing University of Chinese Medicine, Beijing 100700, China

2 Department of Nephrology, Guangdong Provincial Hospital of Chinese Medicine, The Second Affiliated Hospital of Guangzhou University of Chinese Medicine, 111 Dade Road, Yuexiu District, Guangzhou 510120, Guangdong Province, China

3 The Second Clinical College of Guangzhou, University of Chinese Medicine, Guangzhou 510405, Guangdong Province, China and dyslipidemia might lead to the coexistence of cardiovascular disease and renal dysfunction [1]. Clinical studies have proved that simple renal cysts (SRCs) (Bosniak I) might be correlated with renal dysfunction. SRC patients showed higher incidence of proteinuria, increased serum creatinine and decreased estimated glomerular filtration rate (eGFR) [2-4], and patients with larger cysts tended to be associated with hypertension and rapid decline in renal function $[2,5]$.

SRCs are the most common renal cystic diseases in adults, the prevalence of SRCs was reported to be $7.2-10.5 \%$ in Chinese cohorts, and higher in males and elders $[3,4,6]$. In addition, SRCs might grow in size and number over time $[4,6,7]$. The etiology of SRCs has not been clearly clarified. Some researchers speculated SRCs originated from the diverticula on the distal or collecting tubules [8]. Some researchers conducted clinical studies with small sample size and long-term follow-up of SRCs, but seldom clarified the relationship between growth SRCs and renal dysfunction. Our study compared the clinical characteristics of growth SRCs with non-growth SRCs, 
including serum creatinine, blood pressure, blood lipid levels and so on. The incidence of renal dysfunction in SRCs and risk factors of renal dysfunction in growth SRCs were also investigated.

\section{Methods}

\section{Participants and measurements}

The current retrospective study was carried out in outpatients of nephrology department of the Second Affiliated Hospital of Guangzhou University of Chinese Medicine, from January 1st, 2010 to December 31st, 2019. We included patients meeting the following criteria: (1) 18-79 years old at the initial visit; (2) diagnosed with SRCs by ultrasound and reviewed at least once per year; (3) no surgical intervention; (4) no hereditary nephropathy, such as polycystic kidney disease and tuberous sclerosis; (5) no renal dysfunction, baseline eGFR $>60 \mathrm{~mL} / \mathrm{min} / 1.73$ $\mathrm{m}^{2}$; (6) no severe complications, such as malignant diseases, autoimmune diseases, heart failure and severe liver diseases. We also excluded diabetes patients, because they might progress to diabetic nephropathy, which would significantly affect renal function. A total of 571 patients were included in the current study (Fig. 1).

The following data were collected: age, gender, systolic blood pressure (SBP), diastolic blood pressure (DBP), body mass index (BMI), follow-up period, complications (such as hypertension, hyperuricemia (HUA), hypercholesterolemia, hypertriglyceridemia, nephrolithiasis and hematuria) and laboratory examinations (serum creatinine, eGFR, serum uric acid (SUA), total cholesterol (TC), triglyceride (TG)). The ethics committee of Guangdong

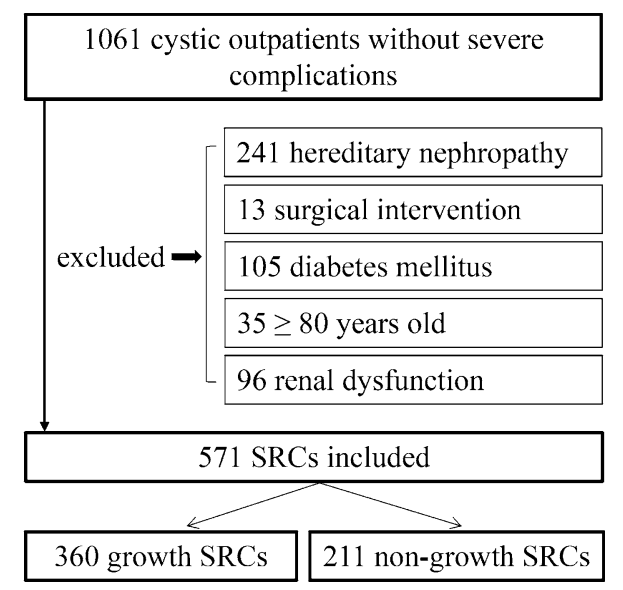

Fig. 1 Details of the included patients
Provincial Hospital of Chinese Medicine approved the study (YE2019-197-01).

\section{Definition of SRCs, renal dysfunction, hypertension, hyperuricemia, dyslipidemia, hematuria and nephrolithiasis}

SRCs were defined as a rounded or oval mass of homogeneous anechoic content, with marked posterior enhancement, smooth well-delimited margins, and an imperceptible sub-millimeter wall on ultrasound [9]. We defined multiple renal cysts for cyst number $\geq 2$, large cysts for cyst diameter $\geq 20 \mathrm{~mm}$, growth renal cysts for cyst diameter increased more than $5 \%$ of the basic or increased in number during the follow-up. Yearly change in maximum diameter of SRCs $=($ final maximum diameter-baseline maximum diameter)/follow-up duration. BMI was calculated as the weight $(\mathrm{kg})$ divided by the square of the height $\left(\mathrm{m}^{2}\right)$. According to MDRD formula, eGFR ( $\mathrm{mL} / \mathrm{min} / 1.73$ $\left.\mathrm{m}^{2}\right)=175 \times(\text { serum creatinine } / 88.4)^{-1.234} \times \mathrm{age}^{-0.179}$ [ $\times 0.79$ (if female)] [10], we defined eGFR $<60 \mathrm{~mL} /$ $\min / 1.73 \mathrm{~m}^{2}$ for renal dysfunction. Hypertension was defined as $\mathrm{SBP} \geq 140 \mathrm{mmHg}$ and/or $\mathrm{DBP} \geq 90 \mathrm{mmHg}$, or by self-reported history of hypertension, or by the use of antihypertensives. Hyperuricemia was defined as SUA $\geq 420 \mu \mathrm{mol} / \mathrm{L}$ in male or $\geq 360 \mu \mathrm{mol} / \mathrm{L}$ in female, or by self-reported history of HUA, or by the use of uratelowering therapy. Dyslipidemia was defined as total cholesterol $\geq 5.20 \mathrm{mmol} / \mathrm{L}$ and/or triglyceride $\geq 1.70 \mathrm{mmol} / \mathrm{L}$, or by self-reported history of hypercholesterolemia or hypertriglyceridemia, or by the use of lipid-lowering drugs. Hematuria was defined as $\geq 3$ red blood cells per high-powered field (HPF) by urine dipstick testing. Nephrolithiasis was defined as echogenic focus that with or without acoustic shadowing on ultrasound.

\section{Statistical analysis}

Data were presented as mean \pm standard or median (interquartile range) for continuous variables, and proportions for categorical variables. We used independent-samples $t$ test or Mann-Whitney $U$ test for continuous variables, and $\chi^{2}$ test for categorical variables to compare the differences in demographic and clinical variables between different groups. We used multivariable logistic regression analysis to estimate risk factors associated with renal dysfunction in growth SRCs group. SPSS version 23.0 was used for all statistical analysis with two tailed $P$ values of 0.05 . Kaplan-Meier and log-rank test were used for prevalence of renal dysfunction between growth SRCs group and non-growth SRCs group, using GraphPad Prism 8.0.2. 


\section{Results}

\section{Demographic characteristics among different groups}

Among 571 patients, the mean baseline age was $51.31 \pm 14.37$ years, ranging from 19 to 79 years, and $329(57.6 \%)$ of them were male. The median follow-up duration was 3 years, ranging from 1 to 10 years. Followup characteristics of the cohort stratified according to the development of SRCs are shown in Table 1. In the whole cohort, none of them progressed to a malignant cyst during the follow-up, and none of them decreased or disappeared, the final maximum diameter increased $1 \mathrm{~mm}$ (2.74\%) per year. 353 patients increased in cyst size, 40 patients increased in cyst number, and 33 increased in both size and number. Finally, 360 patients were included in growth SRCs group. In growth SRCs group, the final maximum diameter increased $1.67 \mathrm{~mm}$ (6.25\%) per year. In growth SRCs group, the mean age was $52.44 \pm 14.42$ years, while in non-growth SRCs group, the mean age was $58.06 \pm 13.33$ years. Patients in growth SRCs group tented to have higher percentage of hypertension $(47.8 \%$ vs. $12.3 \%, P<0.001)$, hematuria $(24.7 \%$ vs. $13.3 \%, P=0.001)$, large cyst $(81.9 \%$ vs. $34.1 \%, P<0.001)$ and multiple cysts $(43.6 \%$ vs. $25.1 \%, P<0.001)$ compared with non-growth SRCs group. Age, SBP, DBP and final maximum diameter were significantly different between growth SRCs group and non-growth SRCs group (all $P<0.001)$.

\section{Prevalence of renal dysfunction in SRCs}

The mean baseline serum creatinine was $78.57 \pm 16.23 \mu \mathrm{mol} / \mathrm{L}$, and the mean baseline eGFR was $96.42 \pm 23.63 \mathrm{~mL} / \mathrm{min} / 1.73 \mathrm{~m}^{2}$ in the whole cohort. As shown in Table 1, the prevalence of renal dysfunction was $15.6 \%$ (89/571) after the follow-up. The prevalence of renal dysfunction was $23.3 \%$ in growth SRCs group and $2.4 \%$ in non-growth one, with a significant difference between them $(P<0.001)$. The mean serum creatinine was $97.39 \pm 20.90 \mu \mathrm{mol} / \mathrm{L}$ in growth SRCs group, and $79.82 \pm 15.24 \mu \mathrm{mol} / \mathrm{L}$ in non-growth SRCs group. The mean eGFR was $73.47 \pm 19.62 \mathrm{~mL} / \mathrm{min} / 1.73 \mathrm{~m}^{2}$ in growth SRCs group, and $93.10 \pm 23.32 \mathrm{~mL} / \mathrm{min} / 1.73 \mathrm{~m}^{2}$ in nongrowth SRCs group. Serum creatinine and eGFR were significantly different between growth SRCs group and non-growth SRCs group (both $P<0.001$ ). The probability of free survival of renal dysfunction based on the development of SRCs in the Kaplan-Meier analysis showed significant differences, as shown in Fig. 2.

\section{Demographic and clinical characteristics between renal dysfunction and normal renal function in growth SRCs}

As shown in Table 2, growth SRCs patients with renal dysfunction were more likely to be older $(57.67 \pm 13.36$ vs. $50.85 \pm 14.38$ years old $)$, female $(60.7 \%$ vs. $40.9 \%)$, hypertension ( $71.4 \%$ vs. $40.6 \%)$, HUA (56.0\% vs. $30.8 \%)$, hypercholesterolemia $(78.6 \%$ vs. $46.4 \%)$, hypertriglyceridemia ( $44.0 \%$ vs. $27.5 \%)$ and large cyst $(97.6 \%$ vs. $77.2 \%)$, with higher levels of SBP $(146.46 \pm 18.75$ vs. $134.46 \pm 17.33 \mathrm{mmHg}), \quad$ DBP $(87.49 \pm 11.40$ vs. $79.98 \pm 11.98 \mathrm{mmHg})$, SUA $(386.23 \pm 107.15$ vs. $353.16 \pm 104.13 \mu \mathrm{mol} / \mathrm{L})$, TC $(6.39 \pm 1.53$ vs. $5.11 \pm 1.59 \mathrm{mmol} / \mathrm{L})$, TG (1.63 vs. $1.24 \mathrm{mmol} / \mathrm{L})$, larger final maximum diameter ( 49 vs. $31 \mathrm{~mm}$ ) and larger yearly change in maximum diameter ( 2.16 vs. $1.50 \mathrm{~mm} /$ year), with significant differences compared with normal renal function group (all $P<0.05$ ). After adjusted for the confounding factors, using multivariable logistic regression analysis, renal dysfunction was associated with age (OR 1.031, 95\% CI 1.008-1.055), female (OR 3.739, 95\% CI 2.002-6.983), TC (OR 1.574, 95\% CI 1.301-1.905), DBP (OR 1.036, 95\% CI 1.008-1.065), final maximum diameter (OR $1.017,95 \%$ CI $1.002-1.032$ ) and yearly change in maximum diameter (OR $1.238,95 \%$ CI 1.048-1.462) (Table 3).

\section{Discussion}

To our best knowledge, the current study had the largest SRC sample size in Chinese outpatients. We found higher rate of renal dysfunction compared with another Chinese research after follow-up (15.6\% vs. 3.8\%) [2]. Such difference may be related to the source of patients. In our study, all patients visited nephrology outpatient department rather than health examination center. It is worth noting that the prevalence of renal dysfunction was about 10 times higher in growth SRCs group compared with non-growth SRCs group in our cohort study participants ( $23.3 \%$ vs. $2.4 \%$ ).

The reliability of diagnosing SRCs by ultrasound is approximately $100 \%$ [9], the current study only used ultrasound results to evaluate the development of SRCs. But the measurement of the maximum diameter of SRCs by ultrasound has the intrapersonal or interpersonal variability. The limitation of measurement for the diameter of SRCs by ultrasound exists, and therefore, the judgment of growth SRCs also has uncertainty. In general, SRCs are asymptomatic, they rarely progress to malignant cysts $[6,7,11]$. However, more than half of our patients complained of low back pain or hematuria in varying degrees. Growth SRCs showed higher proportion of hematuria than non-growth SRCs after follow-up (24.7\% vs. $13.3 \%$ ). Large cysts ( $81.9 \%$ vs. $34.1 \%$ ) 
Table 1 The demographics and clinical characteristics of growth and non-growth SRCs

\begin{tabular}{|c|c|c|c|c|}
\hline & $\begin{array}{l}\text { All patients } \\
(n=571)\end{array}$ & $\begin{array}{l}\text { Growth SRCs } \\
(n=360)\end{array}$ & Non-growth SRCs $(n=211)$ & ${ }^{*} P$ value \\
\hline \multicolumn{5}{|l|}{ Age, year } \\
\hline Baseline & $51.31 \pm 14.37$ & $48.98 \pm 14.31$ & $55.28 \pm 13.62$ & $<0.001$ \\
\hline Final & $54.52 \pm 14.27$ & $52.44 \pm 14.42$ & $58.06 \pm 13.33$ & $<0.001$ \\
\hline Male, $n(\%)$ & $329(57.6)$ & $196(54.4)$ & $133(63.0)$ & 0.045 \\
\hline \multicolumn{5}{|l|}{ BMI, $\mathrm{kg} / \mathrm{m}^{2}$} \\
\hline Baseline & $22.57 \pm 2.86$ & $22.56 \pm 3.09$ & $22.59 \pm 2.41$ & 0.924 \\
\hline Final & $22.65 \pm 2.79$ & $22.62 \pm 2.99$ & $22.69 \pm 2.42$ & 0.755 \\
\hline \multicolumn{5}{|l|}{ SBP, mmHg } \\
\hline Baseline & $130.38 \pm 19.58$ & $130.05 \pm 19.46$ & $130.94 \pm 19.81$ & 0.602 \\
\hline Final & $132.15 \pm 17.91$ & $137.26 \pm 18.36$ & $123.44 \pm 13.16$ & $<0.001$ \\
\hline \multicolumn{5}{|c|}{$\mathrm{DBP}, \mathrm{mmHg}$} \\
\hline Baseline & $79.04 \pm 11.68$ & $78.91 \pm 11.86$ & $79.25 \pm 11.38$ & 0.739 \\
\hline Final & $79.71 \pm 11.56$ & $81.73 \pm 12.25$ & $76.26 \pm 9.33$ & $<0.001$ \\
\hline \multicolumn{5}{|l|}{$\mathrm{Scr}, \mu \mathrm{mol} / \mathrm{L}$} \\
\hline Baseline & $78.57 \pm 16.23$ & $77.50 \pm 15.92$ & $80.39 \pm 16.62$ & 0.039 \\
\hline Final & $90.90 \pm 20.80$ & $97.39 \pm 20.90$ & $79.82 \pm 15.24$ & $<0.001$ \\
\hline \multicolumn{5}{|c|}{$\mathrm{eGFR}, \mathrm{mL} / \mathrm{min} / 1.73 \mathrm{~m}^{2}$} \\
\hline Baseline & $96.42 \pm 23.63$ & $98.10 \pm 23.88$ & $93.54 \pm 22.97$ & 0.026 \\
\hline Final & $80.72 \pm 23.08$ & $73.47 \pm 19.62$ & $93.10 \pm 23.32$ & $<0.001$ \\
\hline \multicolumn{5}{|c|}{$\mathrm{SUA}, \mu \mathrm{mol} / \mathrm{L}$} \\
\hline Baseline & $366.25 \pm 102.24$ & $364.93 \pm 103.53$ & $368.52 \pm 100.19$ & 0.686 \\
\hline Final & $360.78 \pm 104.76$ & $360.88 \pm 105.62$ & $360.61 \pm 103.51$ & 0.976 \\
\hline \multicolumn{5}{|c|}{$\mathrm{TC}, \mathrm{mmol} / \mathrm{L}$} \\
\hline Baseline & $5.06 \pm 1.14$ & $5.04 \pm 1.13$ & $5.10 \pm 1.14$ & 0.572 \\
\hline Final & $5.30 \pm 1.69$ & $5.41 \pm 1.66$ & $5.13 \pm 1.72$ & 0.058 \\
\hline \multicolumn{5}{|c|}{$\mathrm{TG}, \mathrm{mmol} / \mathrm{L}$} \\
\hline Baseline & $1.19(0.87,1.74)$ & $1.19(0.86,1.75)$ & $1.18(0.87,1.70)$ & 0.958 \\
\hline Final & $1.32(0.94,1.82)$ & $1.30(0.92,1.82)$ & $1.34(0.94,1.84)$ & 0.365 \\
\hline \multicolumn{5}{|c|}{ Hypertension, $n(\%)$} \\
\hline Baseline & $209(36.6)$ & $140(38.9)$ & $69(32.7)$ & 0.138 \\
\hline Final & $198(34.7)$ & $172(47.8)$ & $26(12.3)$ & $<0.001$ \\
\hline \multicolumn{5}{|c|}{ Renal dysfunction, $n(\%)$} \\
\hline Final & $89(15.6)$ & $84(23.3)$ & $5(2.4)$ & $<0.001$ \\
\hline \multicolumn{5}{|c|}{ Hyperuricemia, $n(\%)$} \\
\hline Baseline & $193(33.8)$ & $128(35.6)$ & $65(30.8)$ & 0.247 \\
\hline Final & $204(35.7)$ & $132(36.7)$ & $72(34.1)$ & 0.540 \\
\hline \multicolumn{5}{|c|}{ Hypercholesterolemia, $n(\%)$} \\
\hline Baseline & $248(43.4)$ & $155(43.1)$ & $93(44.1)$ & 0.812 \\
\hline Final & $289(50.6)$ & $194(53.9)$ & $95(45.0)$ & 0.041 \\
\hline \multicolumn{5}{|c|}{ Hypertriglyceridemia, $n(\%)$} \\
\hline Baseline & $149(26.1)$ & $96(26.7)$ & $53(25.1)$ & 0.684 \\
\hline Final & $149(26.1)$ & $113(31.4)$ & $63(29.9)$ & 0.702 \\
\hline \multicolumn{5}{|c|}{ Nephrolithiasis, $n(\%)$} \\
\hline Baseline & $180(31.5)$ & $113(31.4)$ & $67(31.8)$ & 0.928 \\
\hline Final & $185(32.4)$ & $118(32.8)$ & $67(31.8)$ & 0.801 \\
\hline \multicolumn{5}{|c|}{ Hematuria, $n(\%)$} \\
\hline Baseline & $93(16.3)$ & $66(18.3)$ & $27(12.8)$ & 0.084 \\
\hline Final & $117(20.5)$ & $89(24.7)$ & $28(13.3)$ & 0.001 \\
\hline
\end{tabular}


Table 1 (continued)

\begin{tabular}{|c|c|c|c|c|}
\hline & $\begin{array}{l}\text { All patients } \\
(n=571)\end{array}$ & $\begin{array}{l}\text { Growth SRCs } \\
(n=360)\end{array}$ & Non-growth SRCs $(n=211)$ & ${ }^{*} P$ value \\
\hline \multicolumn{5}{|l|}{ Maximum diameter, mm } \\
\hline Baseline & $21.00(14.00,38.00)$ & $26.50(16.00,43.00)$ & $17.00(12.00,23.00)$ & $<0.001$ \\
\hline Final & $25.00(16.00,44.00)$ & $34.00(23.00,51.75)$ & $17.00(12.00,23.00)$ & $<0.001$ \\
\hline $\begin{array}{l}\text { Yearly change in maximum } \\
\text { diameter, mm/year }\end{array}$ & $1.00(0.00,2.00)$ & $1.67(1.00,2.50)$ & - & - \\
\hline \multicolumn{5}{|l|}{ Large cyst, $n(\%)$} \\
\hline Baseline & $316(55.3)$ & $244(67.8)$ & $72(34.1)$ & $<0.001$ \\
\hline Final & $367(64.3)$ & $295(81.9)$ & $72(34.1)$ & $<0.001$ \\
\hline \multicolumn{5}{|l|}{ Multiple renal cysts, $n(\%)$} \\
\hline Baseline & $170(29.8)$ & $117(32.5)$ & $53(25.1)$ & 0.063 \\
\hline Final & $210(36.8)$ & $157(43.6)$ & $53(25.1)$ & $<0.001$ \\
\hline
\end{tabular}

$B M I$ body mass index; $S B P$ systolic blood pressure; $D B P$ diastolic blood pressure; $S c r$ serum creatinine; $e G F R$ estimated glomerular filtration rate; $S U A$ serum uric acid; $T C$ total cholesterol; $T G$ triglyceride

*Compared growth SRCs with non-growth SRCs

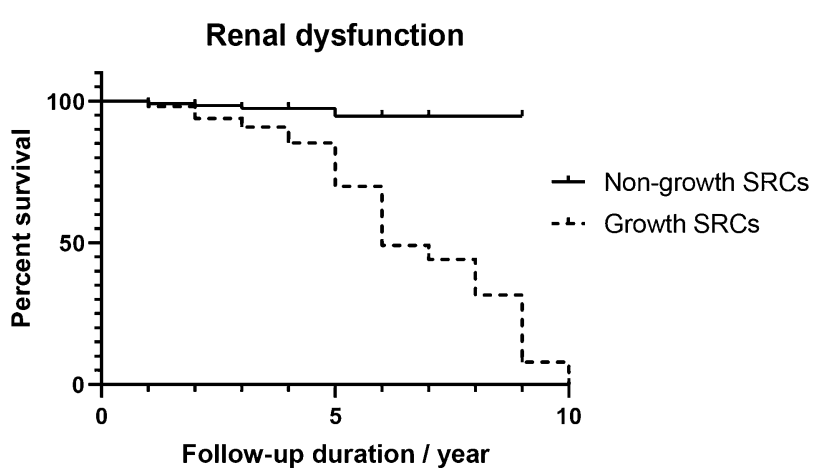

Fig. 2 The $\mathrm{K}-\mathrm{M}$ curve for the free survival of renal dysfunction between growth SRCs and non-growth SRCs $(\log$-rank $P<0.001)$

and multiple cysts (43.6\% vs. $25.1 \%$ ) were more common in growth SRCs compared with non-growth SRCs. In growth SRCs group, the final maximum diameter increased $1.67 \mathrm{~mm}(6.25 \%)$ per year. None of SRCs progressed to a malignant cyst during the follow-up. SRCs were more common in males $[3,4,6]$. In the current cohort, $57.6 \%$ of the patients were male. Liu et al. [12] examined the expression of signal transducer and activator of transcription 3 (STAT3) and androgen receptor in cystic kidneys and normal kidneys, they found strongly activated STAT3 and positive androgen receptor in tubular epithelial cells from cystic kidneys, but rare in normal kidneys. Therefore, they hypothesized that the gender disparity in SRCs might be related to androgenSTAT3 activation. Contrary to expectations, in growth SRCs group, renal dysfunction was significantly related to female (OR 3.739, 95\% CI 2.002-6.983). Further hormone examinations are needed to explain the relationship between gender and renal dysfunction in SRCs. The prevalence of SRCs increases with age $[4,6,13], 56.9 \%$ of our patients were older than 50 years at the initial visit, the age-related incidence might be relevant to the increasing diverticula of renal tubules with aging [14]. It is remarkable that patients in growth SRCs group were younger than non-growth SRCs group $(52.44 \pm 14.42$ vs. $58.06 \pm 13.33$ years). Similarly, Park et al. [7] found the probability of an increase in SRCs was 7.1 times greater in patients $\geq 50$ years old at diagnosis than in those $<50$ years old, but the mean growth rate was lower in patients $\geq 50$ years old.

Kidney cortical volume would decrease and the number and size of SRCs would increase with healthy aging, accompanied with decline of nephron number and decreased renal function [14]. Therefore, the decline in renal function whether caused by SRCs is still controversial. Kwon et al. [5] used dimercaptosuccinic acid renal scans to examine cystic kidney function compared with the contralateral normal kidney. They found the relative renal function values of the cystic kidney were significantly lower than the contralateral kidney in SRCs group, but there were no differences between two kidneys in normal kidney group. Another research investigated the effect of cysts on living renal transplantation function [15]. It found allograft functions were both normal in cyst group and non-cyst group, but cysts in donor kidney could affect allograft function, and cystic donors had more sclerotic glomeruli than non-cyst group. Other researches declared that SRCs were associated with higher incidence of proteinuria, increased serum creatinine and decreased eGFR [2-4]. All the above showed negative effects of SRCs on renal function. However, Ozdemir et al. [16] suggested that SRCs had no effect on renal dysfunction. Waldram et al. [17] found kidneys with cysts had lower baseline eGFR but similar yearly change in eGFR compared to those without cysts. The creatinine credibility as endogenous biomarker is also exposed in recent conducted 
Table 2 Demographics and clinical characteristics between renal dysfunction and normal renal function in growth SRCs
Table 3 Multivariable logistic regression analysis for association between demographics and renal dysfunction in growth SRCs

\begin{tabular}{lllr}
\hline & $\begin{array}{l}\text { Renal dysfunction } \\
(n=84)\end{array}$ & Normal renal function $(n=276)$ & $P$ value \\
\hline Age, year & $57.67 \pm 13.36$ & $50.85 \pm 14.38$ & $<0.001$ \\
Male, $n(\%)$ & $33(39.3)$ & $163(59.1)$ & 0.001 \\
BMI, $\mathrm{kg} / \mathrm{m}^{2}$ & $22.08 \pm 2.48$ & $22.79 \pm 3.11$ & 0.056 \\
SBP, $\mathrm{mmHg}$ & $146.46 \pm 18.75$ & $134.46 \pm 17.33$ & $<0.001$ \\
DBP, $\mathrm{mmHg}$ & $87.49 \pm 11.40$ & $79.98 \pm 11.98$ & $<0.001$ \\
SUA, $\mu$ mol/L & $386.23 \pm 107.15$ & $353.16 \pm 104.13$ & 0.012 \\
TC, mmol/L & $6.39 \pm 1.53$ & $5.11 \pm 1.59$ & $<0.001$ \\
TG, mmol/L & $1.63(1.00,1.90)$ & $1.24(0.91,1.80)$ & 0.011 \\
Hypertension, $n(\%)$ & $60(71.4)$ & $112(40.6)$ & $<0.001$ \\
Hyperuricemia, $n(\%)$ & $47(56.0)$ & $85(30.8)$ & $<0.001$ \\
Hypercholesterolemia, $n(\%)$ & $66(78.6)$ & $128(46.4)$ & $<0.001$ \\
Hypertriglyceridemia, $n(\%)$ & $37(44.0)$ & $76(27.5)$ & 0.004 \\
Nephrolithiasis, $n(\%)$ & $24(28.6)$ & $94(34.1)$ & 0.348 \\
Hematuria, $n(\%)$ & $25(29.8)$ & $64(23.2)$ & 0.221 \\
Final maximum diameter, mm & $49.00(35.25,65.00)$ & $31.00(21.00,47.00)$ & $<0.001$ \\
Yearly change in maximum & $2.16(1.50,3.40)$ & $1.50(1.00,2.50)$ & $<0.001$ \\
diameter, mm/year & & & $<0.001$ \\
Large cyst, $n(\%)$ & $82(97.6)$ & $213(77.2)$ & 0.552 \\
Multiple renal cysts, $n(\%)$ & $39(46.4)$ & $118(42.8)$ & \\
\hline & & & \\
\hline
\end{tabular}

\begin{tabular}{llr}
\hline & ${ }^{a}$ Adjusted OR $(95 \% \mathrm{CI})$ & $P$ value \\
\hline Age, per 1 year increase & $1.031(1.008-1.055)$ & 0.008 \\
Gender, female vs. male & $3.739(2.002-6.983)$ & $<0.001$ \\
TC, per 1 mmol/L increase & $1.574(1.301-1.905)$ & $<0.001$ \\
DBP, per 1 mmHg increase & $1.036(1.008-1.065)$ & 0.012 \\
Large cyst, positive vs. negative & $4.488(0.949-21.219)$ & 0.058 \\
Final maximum diameter, per 1 mm increase & $1.017(1.002-1.032)$ & 0.029 \\
Yearly change in maximum diameter, per 1 mm/year & $1.238(1.048-1.462)$ & 0.012 \\
$\quad$ increase & & \\
\hline
\end{tabular}

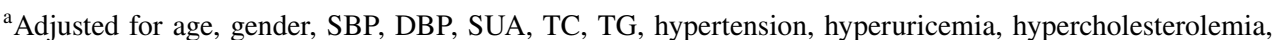
hypertriglyceridemia, final maximum diameter, yearly change in maximum diameter and large cyst research studies as standard eGFR marker $[18,19]$. In our study, the mean serum creatinine of the whole cohort after follow-up was significantly higher than the baseline level $(90.90 \pm 20.80$ vs. $78.57 \pm 16.23 \mu \mathrm{mol} / \mathrm{L})$, the mean serum creatinine of growth SRCs group was significantly higher than non-growth SRCs group after follow-up, and the mean eGFR of growth SRCs group was significantly lower than non-growth SRCs group. Our results showed that renal dysfunction was associated with final maximum diameter and yearly change in maximum diameter in growth SRCs group, therefore, we approved that cyst expansion further aggravated the decline of nephron number, resulted in the rapid decline in renal function.
There was a significantly increased proportion of hypertension in growth SRCs, and renal dysfunction was correlated with blood pressure level in our study. Kim et al. [20] analyzed the relationship between newly SRCs and hypertension, they found SRCs, especially bilateral cysts, multiple cysts, and cysts that maximum diameter larger than $1 \mathrm{~cm}$, were significantly positively related to the incidence of hypertension. Similarly, Lee et al. [21] found the presence of SRCs increased SBP by $2.38 \mathrm{mmHg}$, increased DBP by $1.61 \mathrm{mmHg}$, and multiple cysts and large cysts were closely related to prehypertension and hypertension in adults. Some reports presented that the surgical intervention of SRCs resulted in a reduction of blood pressure [22, 23]. Another 
research indicated that SRCs were associated with increased arterial stiffness [24]. Clinically, arterial stiffness is measured through simultaneous oscillometric measurement of the brachial and ankle pulse wave velocity (baPWV). Wu et al. [24] found SRCs could increase the values of baPWV, and both the size and number of SRCs were positively correlated with an increased value of baPWV. The interaction of hypertension and SRCs is still unclear. It is reported that SRCs might compress renal artery, or cystic expansion lead to renal ischemia, and then activate the renin-angiotensin system, thus result in hypertension [20]. We also discovered that SUA was associated with renal dysfunction in growth SRCs, patients in renal dysfunction group showed higher percentage of HUA compared with normal renal function group. However, these relationships disappeared after adjusted for the confounding factors. Similar to our results, Kwon et al. [5] reported that the decrease in renal function in SRCs was associated with higher SUA levels, they explained that SRCs caused renal dysfunction first and elevated SUA later, and our results seemed to support this hypothesis.

The subjects of the study were all outpatients from nephrology department, which may lead to unavoidable selection bias. In addition, the current retrospective study did not exclude the effects of drugs on the growth of SRCs and it could not express the natural process of SRCs. The existence of SRCs was often overlooked due to its rare progression to significant complications. However, our research found that SRCs were closely related to the decline of renal function and the prevalence of renal dysfunction was about 10 times higher in growth SRCs group than non-growth SRCs group. We recommend close follow-up for growth SRCs.

Funding This study was funded by the National Natural Science Foundation of China (Grant number 81373523).

\section{Declarations}

Conflict of interest The authors declare that there are no conflicts of interest to disclose.

Ethical approval This retrospective study involving human participants was in accordance with the Helsinki Declaration, and also under the approval of the ethics committee of Guangdong Provincial Hospital of Chinese Medicine (YE2019-197-01)

Open Access This article is licensed under a Creative Commons Attribution 4.0 International License, which permits use, sharing, adaptation, distribution and reproduction in any medium or format, as long as you give appropriate credit to the original author(s) and the source, provide a link to the Creative Commons licence, and indicate if changes were made. The images or other third party material in this article are included in the article's Creative Commons licence, unless indicated otherwise in a credit line to the material. If material is not included in the article's Creative Commons licence and your intended use is not permitted by statutory regulation or exceeds the permitted use, you will need to obtain permission directly from the copyright holder. To view a copy of this licence, visit http://creativecommons.org/licenses/by/4.0/.

\section{References}

1. Deferrari G, Cipriani A, La Porta E (2021) Renal dysfunction in cardiovascular diseases and its consequences. J Nephrol 34(1):137-153

2. Chen J, Ma X, Xu D, Cao W, Kong X (2019) Association between simple renal cyst and kidney damage in a Chinese cohort study. Ren Fail 41(1):600-606

3. Kong X, Ma X, Zhang C, Su H, Gong X, Xu D (2018) Increased risk of kidney damage among Chinese adults with simple renal cyst. Int Urol Nephrol 50(9):1687-1694

4. Ozveren B, Onganer E, Türkeri LN (2016) Simple renal cysts: prevalence, associated risk factors and follow-up in a health screening cohort. Urol J 13(1):2569-2575

5. Kwon T, Lim B, You D, Hong B, Hong JH, Kim CS, Jeong IG (2016) Simple renal cyst and renal dysfunction: a pilot study using dimercaptosuccinic acid renal Scan. Nephrology (Carlton) 21(8):687-692

6. Yang B, Qiu C, Wan S, Liu J, Li Q, Mai Z, Zeng T, Liu Y, He W, Zeng G (2020) Long-term follow-up study of the malignant transformation potential of the simple renal cysts. Transl Androl Urol 9(2):684-689

7. Park H, Kim CS (2015) Natural 10-year history of simple renal cysts. Korean J Urol 56(5):351-356

8. Baert L, Steg A (1977) Is the diverticulum of the distal and collecting tubules a preliminary stage of the simple cyst in the adult? J Urol 118(5):707-710

9. Hélénon O, Crosnier A, Verkarre V, Merran S, Méjean A, Correas JM (2018) Simple and complex renal cysts in adults: Classification system for renal cystic masses. Diagn Interv Imaging 99(4): 189-218

10. Ma YC, Zuo L, Chen JH, Luo Q, Yu XQ, Li Y, Xu JS, Huang SM, Wang LN, Huang W, Wang M, Xu GB, Wang HY (2006) Modified glomerular filtration rate estimating equation for Chinese patients with chronic kidney disease. J Am Soc Nephrol 17(10):2937-2944

11. O'Kelly F, McAlpine K, Abdeen N, Keays MA, Leonard MP, Guerra LA (2019) The prevalence, clinicodemographics, and outcomes of incidental and symptomatic renal cysts in a pediatric cohort undergoing ultrasonography. J Urol 202(2):394-399

12. Liu M, Xu YF, Feng Y, Zhai W, Che JP, Xia SQ, Wang GC, Zheng JH (2013) Androgen-STAT3 activation may contribute to gender disparity in human simply renal cysts. Int J Clin Exp Pathol 6(4):686-694

13. Choi JD (2016) Clinical characteristics and long-term observation of simple renal cysts in a healthy Korean population. Int Urol Nephrol 48(3):319-324

14. Hommos MS, Glassock RJ, Rule AD (2017) Structural and functional changes in human kidneys with healthy aging. J Am Soc Nephrol 28(10):2838-2844

15. Qiu W, Jiang Y, Wu J, Huang H, Xie W, Xie X, Chen J, Peng W (2017) Simple cysts in donor kidney contribute to reduced allograft function. Am J Nephrol 45(1):82-88

16. Ozdemir AA, Kapucu K (2017) The relationship between simple renal cysts and glomerular filtration rate in the elderly. Int Urol Nephrol 49(2):313-317

17. Waldram MM, Thomas AG, Yu Y, Holscher CM, Nguyen AQ, Halpern SE, Ottman S, Muzaale AD, Henderson ML, Lentine KL, 
Al Ammary F, Brennan DC, Garonzik-Wang JM, Segev DL, Massie AB (2020) Long-term renal function in living kidney donors with simple renal cysts: A retrospective cohort study. Clin Transplant 34(9):e13905. https://doi.org/10.1111/ctr.13905 (Epub 2020 Aug 13)

18. Khan I, Khan AH, Adnan AS, Sulaiman SAS, Hamzah ABA, Ahmed N, Khan A (2018) Effect of socio-demographic factors on endogenous biomarkers (cystatin $\mathrm{C}$ and creatinine) among elderly chronic kidney disease patients: a cross-sectional study. Int Urol Nephrol 50(6):1113-1121

19. Khan I, Khan AH, Adnan AS, Naqvi AA, Rehman AU, Ahmad N, Ishaqui AA, Bitar AN (2020) Comparison of cystatin C and creatinine-based estimated glomerular filtration rate equations among elderly chronic kidney disease patients attending a tertiary care hospital: a prospective cross-sectional study. Clin Nephrol 93(5):217-226

20. Kim SM, Chung TH, Oh MS, Kwon SG, Bae SJ (2014) Relationship of simple renal cyst to hypertension. Korean J Fam Med 35(5):237-242

21. Lee CT, Yang YC, Wu JS, Chang YF, Huang YH, Lu FH, Chang CJ (2013) Multiple and large simple renal cysts are associated with prehypertension and hypertension. Kidney Int 83(5):924-930
22. Ahallal Y, Khallouk A, Tazi MF, Tazi E, Elfassi MJ, Farih MH (2009) Remission of hypertension after treatment of giant simple renal cyst: a case report. Cases J 7(2):9152. https://doi.org/10. 1186/1757-1626-2-9152

23. Zerem E, Imamović G, Omerović S (2009) Simple renal cysts and arterial hypertension: does their evacuation decrease the blood pressure? J Hypertens 27(10):2074-2078

24. Wu HY, Chang YF, Wu IH, Lu FH, Chang CJ, Yang YC, Wu JS (2019) Simple renal cysts are associated with increased arterial stiffness in a Taiwanese population. Hypertens Res 42(7):1068-1073

Publisher's Note Springer Nature remains neutral with regard to jurisdictional claims in published maps and institutional affiliations. 